\title{
Pulmonary Neuroendocrine Cells in Neonatal Rats With Congenital Diaphragmatic Hernia
}

\author{
By H. IJsselstijn, D.G. Perrin, J.C. de Jongste, E. Cutz, and D. Tibboel \\ Rotterdam, The Netherlands and Toronto, Ontario
}

\begin{abstract}
- Lung hypoplasia and persistent pulmonary hypertension are the principal causes of high mortality and morbidity in infants with congenital diaphragmatic hernia (CDH). Amineand peptide-producing pulmonary neuroendocrine cells (PNEC), widely distributed throughout the airway mucosa, are thought to play an important role in both pulmonary development and regulation of pulmonary vascular tone. Furthermore, recent studies show increased levels of calcitonin gene-related peptide (CGRP), a pulmonary vasodilator produced by PNEC, during chronic hypoxia. The article reports data on morphometric analysis of CGRP immunoreactive PNEC clusters (neuroepithelial bodies, NEB) in a rat model of $\mathrm{CDH}$. CDH was induced in neonatal Sprague Dawley rats by oral administration of 2,4-dichloro-phenyl-p-nitrophenylether (Nitrofen; Rohm Haas, Philadelphia, PA) to the mother at $\mathbf{1 0}$ days of gestation. Sections of lungs from term neonatal rats with and without $\mathrm{CDH}$ and controls were immunostained for CGRP (marker of NEB) with specific antibody against rat CGRP. NEB size and number of NEB/ area of lung were assessed using a semiautomatic image analysis system. In lungs of neonatal rats with $\mathrm{CDH}$, the number of NEB per surface area of lung parenchyma was significantly increased compared with the age-matched controls. Although the mean size of NEB was larger in $\mathrm{CDH}$, the differences were not significant. This is the first study of PNEC in CDH. Whether the phenomenon observed in this study results in altered NEB function including imbalance in vasoactive mediators requires further studies, especially in the human being.
\end{abstract}

Copyright $\odot 1995$ by W.B. Saunders Company

INDEX WORDS: Congenital diaphragmatic hernia; pulmonary neuroendocrine cells; calcitonin gene-related peptide; pulmonary hypertension.

CONGENITAL diaphragmatic hernia (CDH) is a $C$ serious malformation with a high mortality and morbidity caused by pulmonary hypoplasia and pulmonary hypertension. ${ }^{1-3}$ The mortality rate of $40 \%$ to $50 \%$ has not changed during the past few years despite changing concepts in treatment, including delayed surgery and extracorporeal membrane oxygenation (ECMO). ${ }^{4}$ Factors that may contribute to pulmonary hypertension in general as well as in $\mathrm{CDH}$ have been studied intensively. Pulmonary neuroendocrine cells (PNEC), a known source of a variety of biological active compounds, have only been studied recently. These amine- and peptide-producing cells are widely distributed throughout the airway mucosa and are found as solitary cells or as clusters that are called neuroepithelial bodies (NEB). ${ }^{5}$ PNEC are thought to play an important role during lung development ${ }^{5,6}$ and neonatal adaptation, ${ }^{5,7}$ particularly in the regulation of pulmonary vascular tone. ${ }^{8}$ One of the peptides produced by PNEC is calcitonin generelated peptide (CGRP). In human beings, CGRP immunoreactive cells are found from 22 weeks of gestation $^{9}$ mostly within the epithelium of distal conducting airways and in nerves around blood vessels. ${ }^{10}$ Both in rats and in humans CGRP is known to show a potent vasodilatory, $8,10,11$ and a bronchoconstricting activity. Recent studies showed increased levels of intracellular CGRP in chronically hypoxic rats $^{12}$ and in lungs of children with bronchopulmonary dysplasia. ${ }^{13}$ Because PNEC were not previously studied in $\mathrm{CDH}$, we investigated the distribution and frequency of CGRP immunoreactive PNEC in a rat model of $\mathrm{CDH}$ and pulmonary hypoplasia. ${ }^{14}$ The aim of this study was to determine whether these cells and their mediators may play a role in problems associated with $\mathrm{CDH}$ in newborns.

\section{MATERIALS AND METHODS}

Female Sprague-Dawley rats (Harlan Olac, England) were mated overnight (day 0 of gestation). To induce $\mathrm{CDH}$, a subgroup of pregnant rats received orally $100 \mathrm{mg}$ of 2,4-dichloro-phenyl-pnitrophenylether (Nitrofen; Rohm and Haas, Philadelphia, PA), dissolved in $1 \mathrm{~mL}$ of olive oil, on day 10 of gestation. Nitrofen administration induces a left-sided or bilateral diaphragmatic defect in $70 \%$ to $90 \%$ of the offspring using this protocol. The offsprings of the rats without Nitrofen administration served as normal controls. Food and water were supplied ad libitum during the whole period of pregnancy. At gestational day 22 (term) the mother was anesthesized by inhalation of ether and a cesarean section was performed. The fetuses were removed and killed before any breathing occurred. The presence of a diaphragmatic defect was assessed and the lungs, with trachea attached, were removed for histological examination. Three study groups were

From the Department of Pediatric Surgery and the Department of Pediatrics, Division of Respiratory Medicine, Erasmus University and University Hospital/Sophia Children's Hospital, Rotterdam, The Netherlands, and the Department of Pathology and The Research Institute, MRC Lung Development Group, The Hospital for Sick Children, and the University of Toronto, Toronto, Ontario, Canada.

Presented at the 41st Annual International Congress of the British Association of Paediatric Surgeons, Rotterdam, The Netherlands, June 29-July 1, 1994.

Supported by the Netherlands Asthma Foundation, project no. 91.56, and a Medical Research Council of Canada Lung Development Group grant.

Address reprint requests to Professor Dr D. Tibboel, Department of Pediatric Surgery, Sophia Children's Hospital, Dr Molewaterplein 60, 3015 GJ Rotterdam, The Netherlands.

Copyright $\odot 1995$ by W.B. Saunders Company

0022-3468/95/3003-0009\$03.00/0 
included: normal controls $(\mathrm{n}=7)$, rats that developed $\mathrm{CDH}$ $(\mathrm{n}=9)$ and rats without $\mathrm{CDH}($ non- $\mathrm{CDH})(\mathrm{n}=3)$ in the Nitrofen group.

The lungs were fixed by immersion in Davidson's solution (40 vol\% ethanol $100 \%, 5$ vol $\%$ acetic acid $96 \%, 10$ vol\% formaldehyde $37 \%, 45$ vol\% saline; $\mathrm{pH} 7.3$ ) and embedded in paraffin. Immunostaining for CGRP was performed with specific rabbit polyclonal antibody against rat CGRP (CA-08-220, Cambridge Research Biochemicals, Wilmington, DE) using a well-established protocol. ${ }^{15,16}$

Morphometric analysis including measurements of NEB size, number of NEB per section, surface area of lung sections, and frequency of NEB (the number of NEB per $\mathrm{mm}^{2}$ of lung) were performed using Apple Macintosh National Institutes of Health (NIH) Image 1.49 programme.

All values were expressed as mean \pm SEM. Group means were compared using the Student's $t$ test, and significance was accepted at $5 \%$ level.

\section{RESULTS}

All rats except two in the $\mathrm{CDH}$ group had major left-sided or bilateral diaphragmatic defects. Two animals with a small right-sided defect were not included in further analysis. In all groups a positive immunostaining for CGRP was detected. More prominent and numerous NEBs were found in the lungs of $\mathrm{CDH}$ rats (Fig 1A) compared with normal controls (Fig 1B).

The findings of the morphometric analysis are summarized in Table 1 . The pulmonary area in rats exposed to Nitrofen was significantly smaller compared with that of controls $(P<.001)$, and in $\mathrm{CDH}$ it was significantly smaller than in non-CDH rats $(P<.01)$. The number of NEB per $\mathrm{mm}^{2}$ of lung area in rats with $\mathrm{CDH}$ was significantly greater compared with that of both other groups $(P<.01$ compared with controls, $P<.05$ compared with non-CDH). Furthermore, the mean size of NEB was greater in $\mathrm{CDH}$ rats, but this was not statistically significant.

\section{DISCUSSION}

Our findings suggest that in rats with $\mathrm{CDH}$ and pulmonary hypoplasia there is a proportionally higher number of NEB immunostained for CGRP. Nitrofenexposed animals without $\mathrm{CDH}$ had a smaller lung area compared with normal controls. However, the relative frequency of NEB per $\mathrm{mm}^{2}$ of lung was comparable to the frequency of NEB seen in controls. This suggests that in $\mathrm{CDH}$ there may be an additional factor apart from the pulmonary hypoplasia with a resulting delayed maturation of lung parenchyma.

With respect to the role of PNEC in lung development, different hypotheses are put forward. Cutz et $\mathrm{al}^{6}$ showed that in the developing human lung the differentiation of PNEC proceeds in a craniocaudal
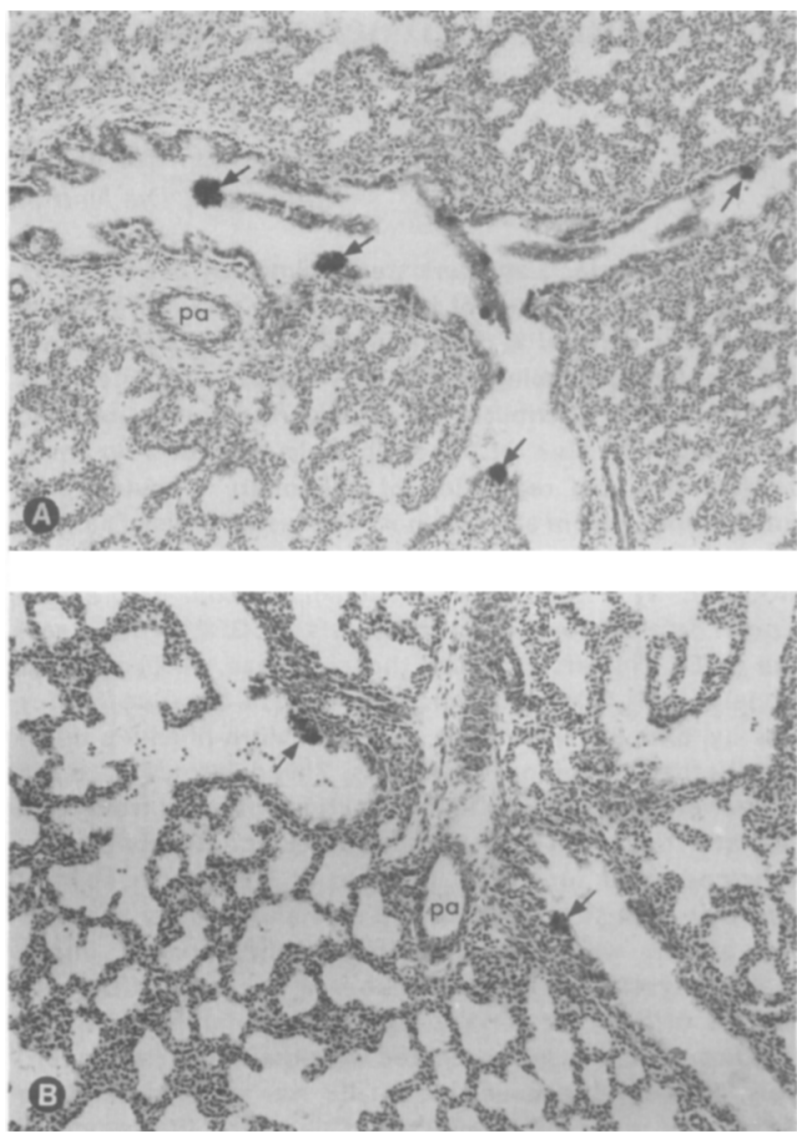

Fig 1. (A) Prominent NEBs (arrows) in the airways of a CDH rat immunostained for CGRP and counterstained with haematoxylin. $\times 125$; pa, pulmonary artery. (B) Fewer NEBs (arrows) are seen in the airways of a normal control rat. Immunostaining as in Fig 1A. (Original magnification $\times 125$ ).

direction with more prominent serotonin-immunoreactive cells during the early stages. In contrast, bombesin-immunoreactive cells reach their maximum number at birth. Spindel et $\mathrm{al}^{17}$ found that levels of GRP, the mammalian homologue of bombesin, increase during gestation and remain elevated until several months after birth, whereas GRP mRNAs reach their maximum levels from 16 to 30 weeks of gestation and then decline by 34 weeks of gestation. Wada et al $^{7}$ studied the developmental changes in the

Table 1. Morphometric Analysis of Lungs of Neonatal Rats With CDH Immunostained for CGRP

\begin{tabular}{lccc}
\hline & $\mathrm{CDH}(\mathrm{n}=7)$ & Non-CDH $(\mathrm{n}=3)$ & Control $(\mathrm{n}=7)$ \\
\hline NEB size $(\mu \mathrm{m})$ & $843.1 \pm 67.6$ & $767.7 \pm 94.2$ & $737.5 \pm 40.9$ \\
Number of NEB & $20.9 \pm 2.2$ & $16.3 \pm 1.2^{*}$ & $30 \pm 4.3$ \\
Area of lung $\left(\mathrm{mm}^{2}\right)$ & $22.2 \pm 1.1^{*} \dagger$ & $29.8 \pm 3.8^{*}$ & $51.4 \pm 1.2$ \\
$\begin{array}{l}\text { Number of NEB per } \\
\mathrm{mm}^{2} \text { lung }\end{array}$ & $0.95 \pm 0.11^{*} \dagger$ & $0.52 \pm 0.04$ & $0.58 \pm 0.07$ \\
\hline
\end{tabular}

*Significantly different from control.

tSignificantly different from non-CDH. 
expression of the CGRP gene in rat lungs. CGRPpositive cells did not appear in lung tissue before the 18th day of gestation and declined within 1 week after birth. These studies suggest involvement of PNEC in normal lung development and a possible role for CGRP in pulmonary adaptation from late intrauterine stages to the early neonatal period.

Earlier studies from our group in rats showed that morphologically hypoplastic lungs are less mature near term. ${ }^{18}$ It can be assumed that in $\mathrm{CDH}$ the immaturity of the lungs is also reflected in the number of NEB. The findings of Wada et $\mathrm{al}^{7}$ do not support this assumption. Further studies are required to show whether our findings reflect immaturity of the lung in $\mathrm{CDH}$ or reffect that a new characteristic of the lung in $\mathrm{CDH}$ has now been discovered.

Stahlman et al $^{19}$ performed a study of colocalization of peptide hormones in PNEC of human fetuses and newborns. They showed that in normal fetuses the percentage of granules labeled for CGRP was consistently lower compared with abnormal fetuses and children dying from pulmonary disease. This percentage increased with the severity of pathological changes, being highest in hyaline membrane disease and bronchopulmonary dysplasia.

Springall et al ${ }^{12,16}$ described an increase in intracellular levels of CGRP in PNEC of hypoxic rats. This could have important implications in the vasoconstrictor response to hypoxia. Furthermore, Youngson et $\mathrm{al}^{20}$ showed that NEB are transducers of the hypoxic stimulus and therefore may function as airway chemoreceptors in the regulation of respiration. In our experiment the neonatal rats were killed immediately after a cesarean section before severe hypoxia after birth could occur. The adaptation from intrauterine to extrauterine life is unlikely to explain our findings for the same reason. A process already existing in utero may result in the higher number of NEB seen in $\mathrm{CDH}$. The immunoreactivity of PNEC in $\mathrm{CDH}$ in humans is presently being investigated.

Whether an altered NEB function, including imbalance in vasoactive mediators, is involved in the continuing high mortality and morbidity of $\mathrm{CDH}$ is still unclear. Further studies in rats and in humans with other mediators such as serotonin are now being performed in our department.

\section{REFERENCES}

1. Kitagawa M, Hislop A, Boyden EA, et al: Lung hypoplasia in congenital diaphragmatic hernia. Br J Surg 58:342-346, 1971

2. George DK, Cooney TP, Chiu BK, et al: Hypoplasia and immaturity of the terminal lung unit (acinus) in congenital diaphragmatic hernia. Am Rev Respir Dis 136:947-950, 1976

3. Naeye RL, Stochat SJ, Whitman V, et al: Unexpected pulmonary vascular abnormalities associated with diaphragmatic hernia. Pediatrics 58:902-906, 1976

4. Tibboel D, Bos AP, Hazebroek FWJ, et al: Changing concepts in the treatment of congenital diaphragmatic hernia. Klin Padiatr 205:67-70, 1993

5. Cutz E: Neuroendocrine cells of the lung. An overview of morphologic characteristics and development. Exp Lung Res 3:185-208, 1982

6. Cutz E, Gillan JE, Bryan AC: Neuroendocrine cells in the developing human lung: Morphologic and functional considerations. Pediatr Pulmonol 1[suppl]:S21-S29, 1985

7. Wada C, Hashimoto C, Kameya $T$, et al: Developmentally regulated expression of the calcitonin gene related peptide (CGRP) in rat lung endocrine cells. Virchows Archiv B Cell Pathol $55: 217-223,1988$

8. Adnot $\mathrm{S}$, Cigarini I, Herigault R, et al: Effects of substance $\mathrm{P}$ and calcitonin gene-related peptide on the pulmonary circulation. J Appl Physiol 70:1707-1712, 1990

9. Tsutsumi Y: Immunohistochemical analysis of calcitonin and calcitonin gene-related peptide in human lung. Hum Pathol 20:896-902, 1989

10. Johnson DE, Wobken JD: Calcitonin gene-related peptide immunoreactivity in airway epithelial cells of the human fetus and infant. Cell Tissue Res 250:579-583, 1987

11. Brain SD, Williams TJ, Tippins JR, et al: Calcitonin generelated peptide is a potent vasodilator. Nature 313:54-56, 1985
12. Springall DR, Polak JM: Calcitonin gene-related peptide and pulmonary hypertension in experimental hypoxia. Anat Rec 236:96-104, 1993

13. Johnson DE, Lock JE, Elde RP, et al: Pulmonary neuroendocrine cells in hyaline membrane disease and bronchopulmonary dysplasia. Pediatr Res 16:446-454, 1982

14. Kluth D, Kangah $R$, Reich $P$, et al: Nitrofen-induced diaphragmatic hernias in rats: An animal model. J Pediatr Surg 25:850-854, 1990

15. Sternberger LA, Sternberger BK (eds): The unlabelled antibody peroxidase antiperoxidase (PAP) method. Immunocytochemistry, ed 2. New York, NY, John Wiley, 1979, pp 104-169

16. Springall DR, Collina G, Barer G, et al: Increased intracellular levels of calcitonin gene-related peptide-like immunoreactivity in pulmonary neuroendocrine cells of hypoxic rats. J Pathol 155:259-267, 1988

17. Spindel ER, Sunday ME, Hofler $H$, et al: Transient elevation of messenger RNA encoding gastrin-releasing peptide, a putative growth factor in human fetal lung. J Clin Invest 80:1172 1179,1987

18. Brandsma AE, Tibboel D, Vulto IM, et al: Ultrastructural features of alveolar epithelial cells in the late fetal pulmonary acinus: A comparison between normal and hypoplastic lungs using a rat model of pulmonary hypoplasia and congenital diaphragmatic hernia. Microscop Res Techn 26:389-399, 1993

19. Stahlman MT, Gray ME: Colocalization of peptide hormones in neuroendocrine cells of human fetal and newborn lungs: An electron microscopic study. Anat Rec 236:206-212, 1993

20. Youngson C, Nurse C, Yeger H, et al: Oxygen sensing in airway chemoreceptors. Nature 365:153-155, 1993 